\title{
Editorial: Source and Effects of Light to Moderate Magnitude Earthquakes
}

\author{
Nicola Alessandro Pino ${ }^{1 *}$, Vincenzo Convertito ${ }^{1}$, Jorge M. Gaspar-Escribano ${ }^{2}$ and \\ Ruizhi Wen ${ }^{3}$ \\ ${ }^{1}$ Istituto Nazionale di Geofisica e Vulcanologia, Osservatorio Vesuviano, Napoli, Italy, ${ }^{2}$ Escuela Técnica Superior de Ingenieros en \\ Topografía, Geodesia y Cartografía, Universidad Politécnica de Madrid, Madrid, Spain, ${ }^{3}$ Institute of Engineering Mechanics, China \\ Earthquake Administration Harbin, Harbin, China
}

Keywords: earthquake source, strong ground motion, historical earthquake catalogue, seismic hazard, damage scenarios

Editorial on the Research Topic

\section{Source and Effects of Light to Moderate Magnitude Earthquakes}

The predominant tectonic stress is generally released with strong earthquakes, which represent the principal element determining the seismic hazard in a region. However, major seismic events are less frequent and have relatively long return periods, typically hundreds to thousands of years. In 2000-2020 the worldwide occurrence of earthquakes with $M \geq 6.0$ was $152 / \mathrm{yr}$ on average, with the annual number ranging from $111 / \mathrm{yr}$ to $205 / \mathrm{yr}$ (https://www.usgs.gov/natural-hazards/ earthquake-hazards/lists-maps-and-statistics). On a planetary scale, the frequency of occurrence of light to moderate magnitude $(4.0 \leq M \leq 5.9)$ earthquakes is about two orders of magnitude larger than the stronger ones (Gutenberg and Richter, 1941). Thus, the investigation of their source represents a fundamental tool in the definition of active structures, and in the assessment of the stress level. Valuable indications on the characteristics of propagation of the seismic waves that contribute to determine the level of ground shaking derive from their analysis. Moreover, statistical investigations on the occurrence of light to moderate magnitude earthquakes, in time and space, are essential in the definition of the seismic hazard and themselves represent a threat to society, leading to injuries, possible casualties, and economic loss through structural and non-structural damage.

On the other hand, due to the low signal-to-noise ratio in their recording and to the lower level of permanent damage, the analysis of these relatively weaker earthquakes, either instrumental or macroseismic, often requires the development of specific methods to derive robust information.

Based on the above considerations we proposed to Frontiers in Earth Science a Research Topic that could encompass various aspects of the analysis of light to moderate magnitude earthquakes. The 2020-2021 world pandemic situation forced most researchers to work from home and to drastically reduce the profitable interaction with colleagues. Nevertheless the scientific community responded with interest and we could close the Research Topic with twelve articles published, involving sixty-five authors from 16 research institutions, distributed in seven countries (Figure 1A).

Most articles deal with the investigation of the source of specific earthquakes (Figure 1B), several of which occurred close to densely inhabited areas and caused casualties and intense damage in spite of their moderate magnitude. Some authors focused on the analysis of waveforms to retrieve ground motion parameters for selected areas, highlighting the larger difficulties to be faced in dealing with smaller earthquakes. Macroseismic studies of historical earthquakes and the development of damage scenarios are also part of the themes considered in the articles of this Research Topic.

In the following we briefly describe the content and the major results of the papers. 


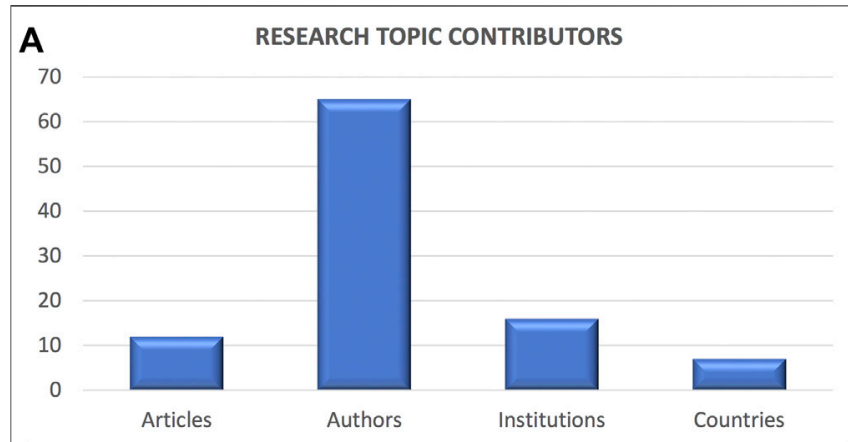

B RESEARCH TOPIC CONTRIBUTES

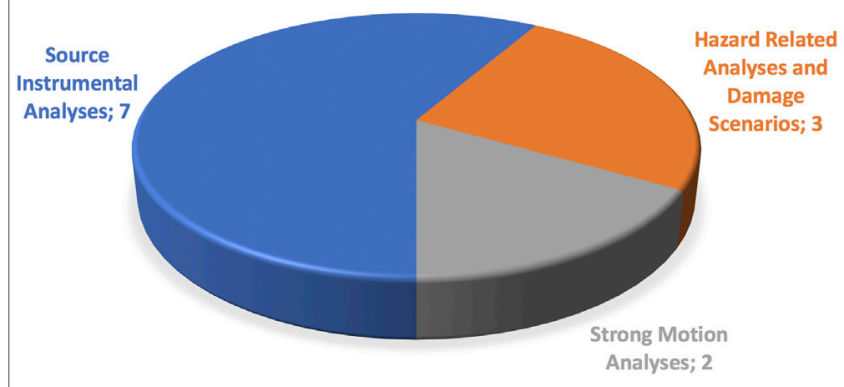

FIGURE 1 | (A) Cumulative graphic description of the authors of the articles included in the present Research Topic, along with their institution and country (B) Rough categorization of the articles by theme.

\section{SOURCE INSTRUMENTAL ANALYSES}

Stich et al. analyze the 2016 southern Alboran Sea earthquake sequence. They carry out a detailed relocation and moment tensor inversion of most events of the series and apparent source time functions for the main shock. They give a detailed description of the rupture and observe slip partitioning into strike-slip rupture and dip-slip aftershocks. They suggest that the 2016 event settled a slip deficit from previous ruptures that could not propagate into the stronger restraining segment.

Wang and Wen, by using of a nonparametric spectral inversion, separated the propagation path attenuation, and source spectra from the observed ground motions recorded in the junction of the northwest Tarim Basin and Kepingtage foldand-thrust zone. The authors observed a slow seismic wave decaying as function of the distance, which reflects the strong anelastic attenuation, and the breakdown of earthquake selfsimilar scaling. They estimated a temporal variation of the stress drops indicating a short-term effect of the mainshock on the source characteristics of the earthquakes before and after the mainshock.

López-Comino et al. studied the 2017, Montesano Earthquake and the possible links with the Val d'Agri oilfield (Italy). They applied advanced seismological techniques to estimate the uncertainties derived from the moment tensor inversion and identify plausible directivity effects. Their findings support the activation of a deeper fault segment associated with the Eastern Agri Fault System and the natural tectonic origin of the Montesano event, rather than an induced or triggering mechanism related to hydrocarbon extraction.

In order to reduce the effect of approximations of the propagation structure in retrieving characteristics of the seismic source, Huo et al. obtained a solution for the event location and the moment tensor of the 2019, $\mathrm{M}_{\mathrm{W}}=5.7$, Changning earthquake by modeling recorded waveforms using 3D Green's functions, including the effect of the topography. The authors also analyzed the effect of their assumptions with respect to solutions obtained with $1 \mathrm{D}$ models without topography.

Ciaccio et al. present a compilation of source mechanisms computed from first motion polarities for more than 100 earthquakes in the magnitude range 4.0-5.5, occurred in Italy in the time period 2015-2016. They also put a focus on two particular areas, for one of which they obtained focal mechanisms for events with magnitude between 3.0 and 3.6, contributing to improve the knowledge of the active tectonics in those areas.

Pastori et al. analysed the 2011-2014 Pollino swarms (Italy). Based on accurate relocations of $\sim 6,000$ earthquakes and shearwave splitting analysis for $\sim 22,600$ event-station pairs, they found two main clusters around the major shocks. They propose a local faulting framework explaining this seismicity and relate it to regional tectonics.

Zhao et al. analyzed seismic data $\mathrm{M}_{L} \geq 2.0$ earthquakes since 2009 near the epicenter of the 3 February $2020 M_{S} 5.1$ Qingbaijiang earthquake in China to investigate the seismogenic structure of the region. The authors indicate that the seismicity along the central and northern segments of the Longquanshan fault zone has occurred mainly along the eastern branch and the $\mathrm{M}_{\mathrm{S}}=5.1$ mainshock is a thrust faulting event based on the focal mechanism solution, and the seismogenic fault lies along the eastern branch of the Longquanshan fault zone.

\section{STRONG MOTION ANALYSES}

Sharma et al. developed stochastic ground motion simulation of two earthquakes occurred in Uttarakhand (India) in 2017 assuming a circular point source with a $\omega^{-2}$ decay (Brune's model). They compared synthetic spectra with the observed Fourier amplitude spectra and find a good match. They also compared observed and simulated PGA values with PGA predictions of well-known GMPEs for different distance ranges and discussed their applicability to the Himalayan region.

Dhakal analyzed 79 Japan earthquakes and derived ground motions parameters for the considered events, highlighting large peak ground acceleration during 15 earthquakes. The author compared the results with predictions from Ground Motion Equations (GMPE) available for the area, concluding that the GMPE underestimate the hazard associated with moderate magnitude events. Finally, focusing on the damaging 2018 North Osaka, $\mathrm{M}_{\mathrm{W}}=5.5$, earthquake, Dhakal suggests that this might have been a high stress drop event. 


\section{Hazard Related Analyses and Damage Scenarios}

Selva et al. reviewed and systematically re-analysed the available historical and instrumental seismic data to build an earthquake catalogue for Ischia (Italy) that includes a robust uncertainties characterization. They assessed data completeness and analysed the spatial, temporal, and magnitude distributions of seismicity in the Ischia area.

Gómez-Novell et al. presented a probabilistic seismic hazard analysis of Southeastern Spain explicitly including faults as seismic sources. They incorporated different multi-fault rupture scenarios in a logic tree and evaluated the relative impact of different parameters hazard estimates. They compared their results with recorded ground motion data, results of other studies of the region and with the national seismic code.

Pessina et al. presented an application of a rapid earthquake damage scenario assessment in the area of Mt. Etna (Italy). Using damage data on residential buildings collected after the December 26, 2018 earthquake, they tested different methodological approaches to simulate the damage scenario in the most affected municipalities. They discussed how these approaches are adapted to the target area and highlight their usefulness for emergency planning.

\section{Conclusive Remark}

Overall, the articles published in the present Research Topic highlight the importance of getting deeper knowledge of the

\section{REFERENCES}

Gutenberg, S., and Richter, C. F. (1941). Seismicity of the earth. Geol. Soc. Am. Spec. Pap. 34, 1-131.

Conflict of Interest: The authors declare that the research was conducted in the absence of any commercial or financial relationships that could be construed as a potential conflict of interest.

Publisher's Note: All claims expressed in this article are solely those of the authors and do not necessarily represent those of their affiliated organizations, or those of characteristics of light to moderate magnitude earthquake, in terms of either stress release or effect on the anthropic environment, at the same time evidencing the complexity of such events. We hope that the results of this Research Topic will increase the interest of the scientific community in such earthquakes, in particular boosting the development of multidisciplinary techniques able to get deeper comprehension of these anyhow damaging events.

\section{AUTHOR CONTRIBUTIONS}

NP, VC, JG-E, and RW edited the Research Topic "Source and Effects of Light to Moderate Magnitude Earthquakes", and equally contributed the Editorial.

\section{ACKNOWLEDGMENTS}

We thank all the authors that submitted their manuscript to the research topic. In times when many scientists don't feel reviewing scholars manuscript as an essential part of the researcher's job, we are really grateful to the reviewers, which spent their time in reading the original manuscripts, providing useful comments and suggestions to improve them. We also thank the editorial staff for their fundamental help and support.

the publisher, the editors and the reviewers. Any product that may be evaluated in this article, or claim that may be made by its manufacturer, is not guaranteed or endorsed by the publisher.

Copyright (c) 2021 Pino, Convertito, Gaspar-Escribano and Wen. This is an openaccess article distributed under the terms of the Creative Commons Attribution License (CC BY). The use, distribution or reproduction in other forums is permitted, provided the original author(s) and the copyright owner(s) are credited and that the original publication in this journal is cited, in accordance with accepted academic practice. No use, distribution or reproduction is permitted which does not comply with these terms. 